\title{
Psychological Distress Screening for Depression, Anxiety and Stress among Medical Ward Patients in Hospital Tapah, Malaysia: A Cross-Sectional Study Using The Depression, Anxiety and Stress Scale (DASS-21)
}

\author{
Xue Ying Yong, B.Pharm. ${ }^{1}$, Chee Fai Sui, M.Pharm. ${ }^{1}$, Mun Yee Liew, B.Pharm. ${ }^{1}$, \\ Teresa Wen San Chong, M.Pharm. ${ }^{1}$, Jeng Young Liew, Ph.D. ${ }^{2}$ \\ 'Pharmacy Department, Hospital Tapah, Tapah 35000, Malaysia. \\ ${ }^{2}$ Faculty of Agro-Based Industry, Universiti Malaysia Kelantan, Jeli 17600, Malaysia. \\ Received 19 June 2021 • Revised 23 July 2021 • Accepted 29 July 2021 • Published online 28 September 2021
}

\begin{abstract}
:
Objectives: The mental health $(\mathrm{MH})$ issue has emerged as one of the great public health concerns worldwide, and its prevalence is escalating substantially among Malaysians. An individual's daily living, physical health, and relationships can be hard-hit by an $\mathrm{MH}$ disorder. The present study aimed to (i) estimate the probable psychological distress in warded adult patients at Hospital Tapah, Malaysia, and (ii) investigate the key antecedents intrinsically linked to depression, anxiety, and stress that may precipitate psychological distress symptoms.
\end{abstract}

Material and Methods: This study was a cross-sectional questionnaire-based study involving 191 participants sampled from the warded adult patients at Hospital Tapah. The psychological distress was assessed using the Depression, Anxiety and Stress Scale-21 (DASS-21). Data were analysed by logistic regression using SPSS 16.0.

Results: Anxiety (34.0\%) was detected as the highest prevalence of probable psychological distress by a wide margin, trailed by stress (16.8\%) and depression (15.2\%). Race, Orang Asli (native people) and mental health awareness were associated with the depression. Respondents who exercised regularly, were employed, non-smokers, non-alcoholic drinkers, and without mental health awareness were at risk of anxiety. Income was found to be significantly associated with stress.

Contact: Xue Ying Yong, B.Pharm.

Pharmacy Department, Hospital Tapah, Tapah 35000, Malaysia.

E-mail: distapah@gmail.com

() 2021 JHSMR. Hosting by Prince of Songkla University. All rights reserved.

This is an open access article under the CC BY-NC-ND license

(http://www.jhsmr.org/index.php/jhsmr/about/editorialPolicies\#openAccessPolicy).
J Health Sci Med Res 2022;40(3):317-333 doi: 10.31584 /jhsmr.2021841 www.jhsmr.org 
Conclusion: This study detected a two-fold increase in the risk of anxiety compared to stress and depression. Further studies should be conducted to identify the factors related to the high DASS-21 scores in detail.

Keywords: mental health, psychological distress, Depression Anxiety Stress Scales (DASS), patient care, health promotion

\section{Introduction}

The World Health Organization (WHO) defines mental health $(\mathrm{MH})$ as "a state of well-being in which an individual realises their own abilities, can cope with normal life stresses, can work productively and fruitfully, and is able to contribute to the community". ${ }^{1} \mathrm{MH}$ disorder is one of the top global health concerns. Efforts to reach psychological resilience have been a stiff challenge to the medical community due to stigma against $\mathrm{MH}$. $\mathrm{MH}$ has been a serious and growing issue in Malaysia for decades, with pervasiveness from $10.7 \%$ in 1996 to $29.2 \%$ in 2015 based on the National Health and morbidity survey (NHMS). ${ }^{2}$ In 2011, the WHO Mental Health Atlas reported that $1.5 \%$ of Malaysian were treated in $\mathrm{MH}$ outpatient facilities. ${ }^{3}$ Nevertheless, the $\mathrm{MH}$ problem nationwide goes unheeded, a situation which can be ascribed to the deprivation of routine psychological distress (PD) screening due to resource scarcities in Malaysia's MH services. 4 Note that a high level of $\mathrm{PD}$ is indicative of impaired $\mathrm{MH}$.

The aging population who suffer from mental illness might be attributed to the chronic illness and the deficit of family support. In contrast, the antecedents of mental illness in the younger generation could be life challenges, drug abuse, domestic violence, etc. With an absence of a fitting instrument to authenticate the biochemical markers, $\mathrm{MH}$ disorder screening, diagnosis and monitoring depend on symptoms and clinical judgement. ${ }^{5}$

The Beck Depression Inventory (BDI), the Depression, Anxiety and Stress Scale-21 (DASS-21), the Patient Health Questionnaire 9 (PHQ-9), and the Hospital
Anxiety and Depression Scale (HADS), to name a few, are standard assessment tools used in Malaysia for evaluating PD symptoms. ${ }^{6}$ The DASS-21, in particular, is obtaining its share of utilisation in health services due to its ease-of-use with multiple languages. The key strength of the DASS-21 is rooted in its capability to assess clinical severity. Using the DASS-21, past research discovered that participants with rheumatological disorders and HIV had the highest prevalences of anxiety. ${ }^{7,8}$

The $\mathrm{MH}$ and mental disorders are not logged anywhere near the similar level of gravity as physical health. To the best of our knowledge, there is a paucity of studies investigating the stressors of $\mathrm{MH}$ disorders among warded patients in Malaysia. Therefore, the present study intended to (i) estimate the prevalence of probable PD among warded adult patients of Hospital Tapah by screening for the levels of depression, anxiety, and stress against the warded adult patients, and (ii) identify the factors associated with depression, anxiety, and stress in warded adult patients in Hospital Tapah. The validated DASS-21 was used.

\section{Material and Methods}

This research used a cross-sectional study conducted at the medical ward in Hospital Tapah for 6 months, from January 2018 until June 2018, the preCoronavirus (COVID-19) era. The DASS-21 is a set of three self-report scales designed to measure the emotional states of depression, anxiety and stress. Each of the three DASS-21 scales contains 7 items, divided into subscales with similar content. The DASS-21 uses a 4-point Likert 
scale of 0 to 3 for measuring each question's severity effect. These numerical values are allotted to the participants' grading: 0=Did not apply to me at all, 1=Applied to me to some degree, or some of the time, $2=$ Applied to me to a considerable degree or good part of time, 3=Applied to me very much or most of the time. Based on the total score, the recommended cut-off scores for conventional severity labels (normal, mild, moderate, severe and very severe) are presented in Table 1.

\section{Participants}

During the 6 months, the male and female medical wards patients were recruited into the study by a convenience sampling method. Patients aged between 18-65 years old who could read and understand the Malay and English languages were considered for the study. The exclusion criteria were terminally ill patients, patients with a history of psychiatric illness, and illiterate patients.
The eligible candidates were requested to selfanswer the DASS-21 questionnaire during bedside counselling or discharge dispensing after giving their preliminary consent. For candidates with difficulty using their upper or lower limbs, the researcher read the statement from the consent form and gained their approval before beginning the survey.

Participants were asked to complete the 21 questions in the DASS-21 questionnaire based on their feelings over the last week within 20 minutes. Each participant's DASS-21 score was subsequently filed and calculated accordingly (Table 1). The screening results were revealed to the participants before they underwent the pre-discharge process. The participants whose scoring mark evidenced probable depression, anxiety, and/or stress were provided a Mental and Physical Health Booklet 2012 for self-monitoring and alerting purposes. Meanwhile, those participants with severe and/or very severe scores were advised to make an

Table 1 Depression, Anxiety and Stress Scale-21 score calculation

\begin{tabular}{|c|c|c|c|c|c|c|c|c|}
\hline & \multicolumn{8}{|c|}{ Stress } \\
\hline Question & Q1 & Q6 & Q8 & Q11 & Q12 & Q14 & Q18 & Total \\
\hline \multicolumn{9}{|l|}{ Score } \\
\hline & \multicolumn{8}{|c|}{ Anxiety } \\
\hline Question & Q2 & Q4 & Q7 & Q9 & Q15 & Q19 & Q20 & Total \\
\hline \multicolumn{9}{|l|}{ Score } \\
\hline & \multicolumn{8}{|c|}{ Depression } \\
\hline Question & Q3 & Q5 & Q10 & Q13 & Q16 & Q17 & Q21 & Total \\
\hline \multicolumn{9}{|l|}{ Score } \\
\hline \multicolumn{9}{|c|}{ Screening score } \\
\hline & & \multicolumn{2}{|c|}{ Depression } & \multicolumn{2}{|c|}{ Anxiety } & \multicolumn{3}{|c|}{ Stress } \\
\hline Normal & & $0-5$ & & $0-4$ & & $0-7$ & & \\
\hline Mild & & $6-7$ & & $5-6$ & & $8-9$ & & \\
\hline Moderate & & $8-10$ & & $7-8$ & & $10-13$ & & \\
\hline Severe & & $11-1$ & & $9-10$ & & $14-17$ & & \\
\hline Very severe & & $15+$ & & $11+$ & & $18+$ & & \\
\hline
\end{tabular}


initial appointment in the Follow-up Clinic in Hospital Tapah. It is necessary to remark that the participants reserved the right to decline to participate in the follow-up counselling session.

The conceptual framework used in this study is shown in Figure 1.

The sample size used in this study was determined using the Raosoft sample size calculator and the Universiti Sains Malaysia (USM) prevalence calculator subject to the $29.2 \% \mathrm{MH}$ prevalence in NMHS. ${ }^{2}$ To achieve a statistical power of $80.0 \%$ at a false positive rate of 0.05 , a population of 7,200 (medical wards) patients in a 6-month period necessitated a sample size of 304 patients. Pre-testing of the data collection form was done to ensure the researchers collected all relevant data correctly. During the inclusion period, only 200 patients participated in the study due to a decreased number of ward admissions. Out of 200 participants, data from 191 participants were analysed as 9 participants were excluded due to incomplete responses.

To provide useful results, a post-hoc power analysis was performed using the ClinCalc calculator. The findings obtained were compared with data $(47.9 \%, 69.6 \%$, and $62.9 \%$ in depression, anxiety, and stress, respectively) from a study with a similar setting (hospital patients with co-morbidities) and the desired power of over $80 \%$ was achieved. $^{9}$

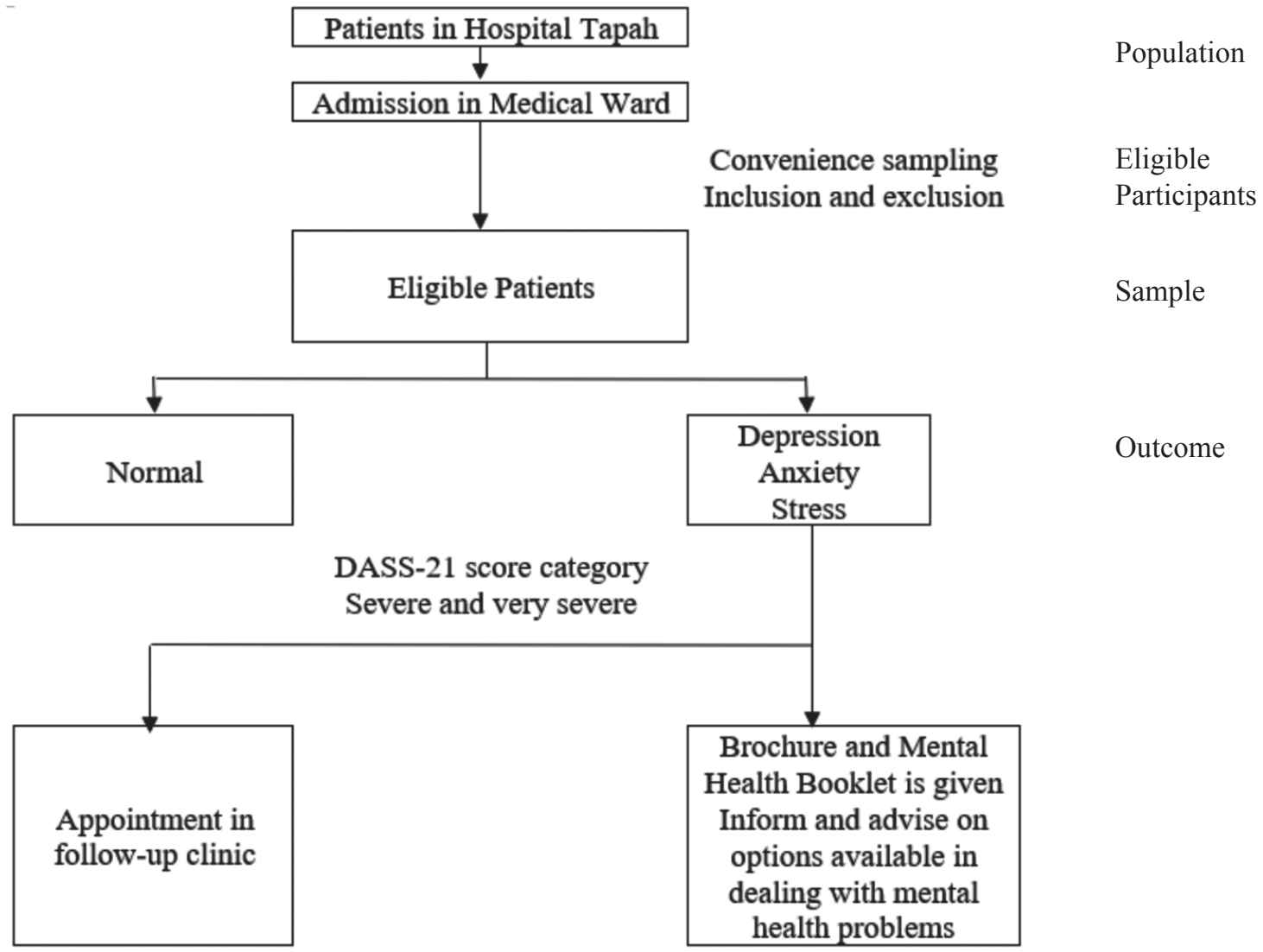

DASS-21=Depression, Anxiety and Stress Scale-21

Figure 1 Conceptual framework 
The data obtained from the DASS-21 survey were analysed using the SPSS 16.0 program. Descriptive statistics were used to summarise the sociodemographic data. The DASS-21 scores were expressed as mean with standard deviation (S.D.); and frequency with percentage to define the prevalences of probable depression, anxiety, and stress in the warded patients. Any variables having a significant bivariate test at 0.25 , a common variable entry criterion, were chosen as potential candidates for the multivariate model. Statistical differences between depression, anxiety, and stress in the warded patients were detected using a multivariate regression analysis at the 0.05 confidence level. Of note, mild to very severe conditions were clustered under one category for the data preceding the binary logistic regression.

This study was registered with the National Medical Research Register (NMRR) with registration number NMRR-17-2999-39085 and approved by the Medical Research Ethics Committee (MREC), Ministry of Health Malaysia. The participation was voluntary, and prior written consent was required using a bilingual Participant Information Sheet and Informed Consent Form especially created for the study. The data were analysed collectively in groups, and there were no identifiable data available in the publication.

The subjects were informed that participation was on a strictly voluntary basis. Questionnaires were distributed to the participants after the informed consent form was signed. All gathered data were confidentially handled and collectively elaborated, having no other purpose than the objectives of this study. The participants were not rewarded and would be given access to the study data upon request when deemed reasonable. The study design assured adequate protection of the participants as the individual participant could not be identified through the questionnaire.

\section{Results}

\section{Sociodemographic characteristics}

The demographic information obtained from the 191 participants included gender, race, age, Body Mass Index (BMI), education, etc. (Table 2) Overall, the warded adult patients were majority females (52.4\%), Malays (57.1\%), married $(70.2 \%)$, and with secondary or below education (77.5\%). Most were out of the labour force $(55.0 \%)$. The respondents' average monthly income was below RM1000 in $56.0 \%$. The mean age of the respondents was 47.53 years, and this explained why the age group from 45-64 years old had the highest percentage among all age groups. The average number for the number of children among the adult patients was at least 3 children (36.1\%). In general, minorities of the participants performed regular exercise (45.0\%), smoked (25.1\%), consumed alcohol (16.8\%), or had $\mathrm{MH}$ awareness (45.5\%). Higher proportions of participants were overweight with BMI $23-28 \mathrm{~kg} / \mathrm{m}^{2}$ (34.6\%), had only 1 comorbidity (30.4\%), or were on at least 3 long-term medications $(46.6 \%)$.

\section{Prevalence of psychological distress and distribution among study participants}

Significant prevalences of symptoms of depression, anxiety, and stress were identified from the study population using the DASS-21 questionnaires. The highest prevalent symptom among the participants was anxiety (34.0\%), followed by stress (16.8\%) and depression (15.2\%) (Table 3). By comparing the severity of the symptoms, higher percentages were found among those who were classified as mild condition in anxiety, stress and depression with $15.2 \%, 9.4 \%$ and $7.3 \%$, respectively. Out of 191 participants, $8.4 \%$ presented symptoms of two mental disorders, and $11.0 \%$ of them experienced symptoms of anxiety, depression and stress simultaneously (Table 4). 
Table 2 Demographic characteristics of participants

\begin{tabular}{|c|c|c|}
\hline \multirow{2}{*}{ Characteristics } & \multicolumn{2}{|c|}{ Patients $(n=191)$} \\
\hline & Number & $\%$ \\
\hline \multicolumn{3}{|l|}{ Gender } \\
\hline Male & 91 & 47.6 \\
\hline Female & 100 & 52.4 \\
\hline \multicolumn{3}{|l|}{ Race } \\
\hline Chinese & 27 & 14.1 \\
\hline Indian & 33 & 17.3 \\
\hline Orang Asli & 22 & 11.5 \\
\hline Malay & 109 & 57.1 \\
\hline \multicolumn{3}{|l|}{ Age (years old) } \\
\hline \multicolumn{3}{|l|}{ Mean (S.D.) $=47.53(16.805)$} \\
\hline$\leq 24$ & 23 & 12.0 \\
\hline $25-44$ & 52 & 27.2 \\
\hline $45-64$ & 81 & 42.4 \\
\hline$\geq 65$ & 35 & 18.3 \\
\hline \multicolumn{3}{|l|}{ BMl } \\
\hline Underweight $(<18.5)$ & 22 & 11.5 \\
\hline Normal weight (18.5-22.9) & 60 & 31.4 \\
\hline Overweight (23-28) & 66 & 34.6 \\
\hline Obese (>28) & 43 & 22.5 \\
\hline \multicolumn{3}{|l|}{ Education } \\
\hline Secondary education or below & 148 & 77.5 \\
\hline Tertiary education & 43 & 22.5 \\
\hline \multicolumn{3}{|l|}{ Performed regular exercise } \\
\hline Yes & 86 & 45.0 \\
\hline \multicolumn{3}{|l|}{ Employment } \\
\hline Working & 69 & 36.1 \\
\hline Unemployed & 17 & 8.9 \\
\hline Out of labour force (student/ & 105 & 55.0 \\
\hline housewife/retired) & & \\
\hline \multicolumn{3}{|l|}{ Marital status } \\
\hline Married & 134 & 70.2 \\
\hline $\begin{array}{l}\text { Single (unmarried/separated/ } \\
\text { widowed) }\end{array}$ & 57 & 29.8 \\
\hline
\end{tabular}

Table 2 (Continued)

\begin{tabular}{|c|c|c|}
\hline \multirow{2}{*}{ Characteristics } & \multicolumn{2}{|c|}{ Patients $(n=191)$} \\
\hline & Number & $\%$ \\
\hline \multicolumn{3}{|l|}{ Number of children } \\
\hline \multicolumn{3}{|c|}{ Mean (S.D.) $=2.0(1.8)$} \\
\hline 0 & 56 & 29.3 \\
\hline 1 & 28 & 14.7 \\
\hline 2 & 38 & 19.9 \\
\hline$\geq 3$ & 69 & 36.1 \\
\hline \multicolumn{3}{|l|}{ Income } \\
\hline$<$ RM1000 or none & 107 & 56.0 \\
\hline RM1000-RM3000 & 66 & 34.6 \\
\hline >RM3000 & 18 & 9.4 \\
\hline \multicolumn{3}{|l|}{ Smoking } \\
\hline Yes & 48 & 25.1 \\
\hline \multicolumn{3}{|l|}{ Alcohol } \\
\hline Yes & 32 & 16.8 \\
\hline \multicolumn{3}{|l|}{ Comorbidity } \\
\hline No & 57 & 29.8 \\
\hline 1 disease & 58 & 30.4 \\
\hline 2 diseases & 56 & 29.3 \\
\hline$\geq 3$ diseases & 20 & 10.4 \\
\hline \multicolumn{3}{|c|}{ Number of long-term medications } \\
\hline No & 61 & 31.9 \\
\hline 1 & 18 & 9.4 \\
\hline 2 & 23 & 12 \\
\hline$\geq 3$ & 89 & 46.6 \\
\hline \multicolumn{3}{|c|}{ Awareness about mental health } \\
\hline Yes & 87 & 45.5 \\
\hline$>65$ years old & 35 & 18.3 \\
\hline
\end{tabular}

S.D.=standard deviation, BMl=body mass index

Table 3 Prevalence of psychological distress and distribution of participants based on the categorisation of their Depression, Anxiety and Stress Scale-21 subscale scores

\begin{tabular}{lllllll}
\hline & & Normal & Mild & Moderate & Severe & Very severe \\
\hline \multirow{2}{*}{ Depression } & Number & 162 & 14 & 9 & 5 & 1 \\
& $\%$ & 84.8 & 7.3 & 4.7 & 2.6 & 0.5 \\
Anxiety & Number & 126 & 29 & 15 & 13 & 8 \\
& $\%$ & 66.0 & 15.2 & 7.9 & 6.8 & 4.2 \\
Stress & Number & 159 & 18 & 8 & 5 & 1 \\
& $\%$ & 83.2 & 9.4 & 4.2 & 2.6 & 0.5 \\
\hline
\end{tabular}


Table 4 Prevalence of psychological distress and distribution of participants based on the combination of their Depression, Anxiety and Stress Scale-21 categories

\begin{tabular}{llllll}
\hline & & $\begin{array}{l}\mathbf{1} \\
\text { Type }^{*}\end{array}$ & $\begin{array}{l}\mathbf{2} \\
\text { Types }^{*}\end{array}$ & $\begin{array}{l}\text { 3 } \\
\text { Types }^{+}\end{array}$ & None \\
\hline Patients & Number & 31 & 16 & 21 & 123 \\
$(\mathrm{n}=191)$ & $\%$ & 16.2 & 8.4 & 11.0 & 64.4 \\
\hline
\end{tabular}

'Stress or Anxiety or Depression only

"Stress+ Anxiety or Anxiety + Depression or Depression + Stress

${ }^{+}$Stress + Depression + Anxiety

\section{Association of sociodemographic factors with}

\section{Psychological Distress}

Table 5 illustrates the sociodemographic factors associated with depression using bivariate and multivariate regression analyses. Both analyses showed that race ( $p$-value $=0.012)$, Orang Asli ( $p$-value $=0.037$ ), and participants without awareness about $\mathrm{MH}(\mathrm{p}$-value=0.005) were significantly associated with depression. The odds of depression of Orang Asli was 3.076 times higher than the other races. Meanwhile, those without awareness exhibited 3.790 higher odds of depression when controlling for race. Table 6 shows the relationship between sociodemographic factors and anxiety. Significant factors unveiled from the bivariate logistics regression analysis included Orang Asli, individuals who performed regular exercise, and nonalcohol consumers. However, different variables were found to be significantly associated with anxiety following the multivariate logistics regression analysis. These factors included respondents who performed regular exercise, who were employed, non-smokers, non-alcohol consumers, and without $\mathrm{MH}$ awareness with p-values of $0.041,0.033$, $0.029,0.047$ and 0.035 , respectively. Higher odds of anxiety symptoms were detected in those who exercised regularly, who were out of labour force, non-smokers, alcohol consumers, and without awareness about mental health. Some variables which were insignificant in bivariate analysis became significant in multivariate analysis, possibly due to imbalance in sample size, missing data, an extremely large group variation relative to between group variation, and the existence of interaction between the variables. ${ }^{10}$

Table 7 demonstrates the factors associated with stress. Income ( $p$-value=0.028) was the only factor that was found to be significantly associated with stress in both analyses. Higher odds were observed in participants who had monthly income less than RM1,000.

In short, the factors associated with depression were race and $\mathrm{MH}$ awareness. Regular exercise, employment, smoked, alcohol consumption and $\mathrm{MH}$ awareness were factors associated with anxiety. Stress was closely aligned to income.

\section{Discussion}

Approximately 450 million people suffer from $\mathrm{MH}$ disorder globally. The extent of the burden of $\mathrm{MH}$ disorders is hard to assess and quantify. ${ }^{1}$ Anxiety is the most common $\mathrm{MH}$ disorder, while depression is the major contributor to disability, as reported by $\mathrm{WHO} .^{11}$ The report from $\mathrm{WHO}$ showed that the proportions of the global population with depression and anxiety in 2015 were estimated to be $4.4 \%$ and $3.6 \%$ respectively. ${ }^{11}$ However, a higher prevalence was detected in anxiety (4.9\%) compared to depression (3.8\%) among Malaysians. ${ }^{11}$ The prevalence of $\mathrm{MH}$ disorders was anticipated to rise dramatically as the COVID-19 outbreak swept swiftly across the world. According to the findings of this study which was conducted prior to the beginning of the COVID-19 pandemic, the occurrences of the main PDs among the warded adult patients in Hospital Tapah were anxiety $(34.0 \%)$, stress $(16.8 \%)$, and depression (15.2\%). The participants were found to have mild symptoms of anxiety, stress, and depression. Our figures can be compared to a recent study done during the COVID-19 epidemic, which found that Malaysians had mean scores 


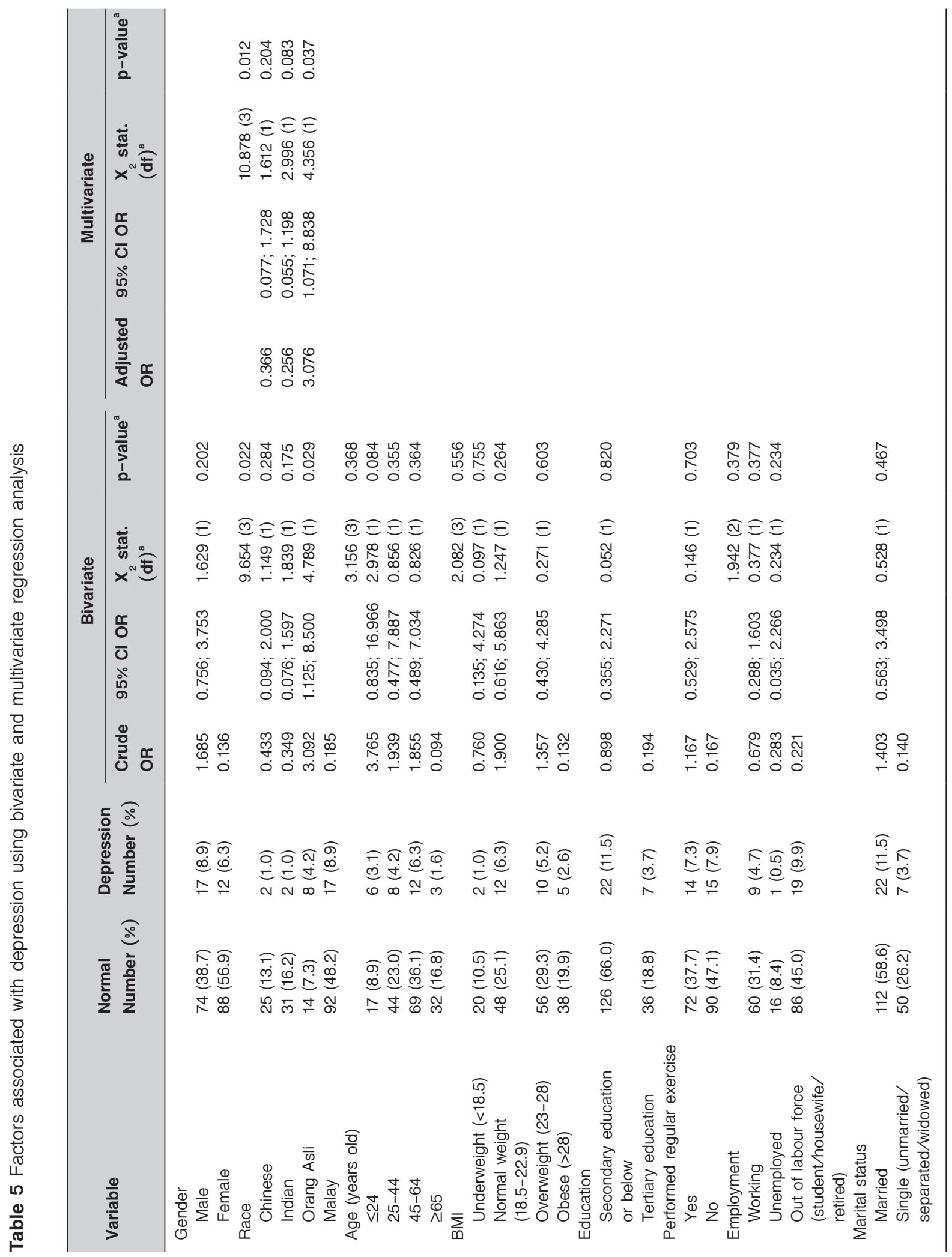




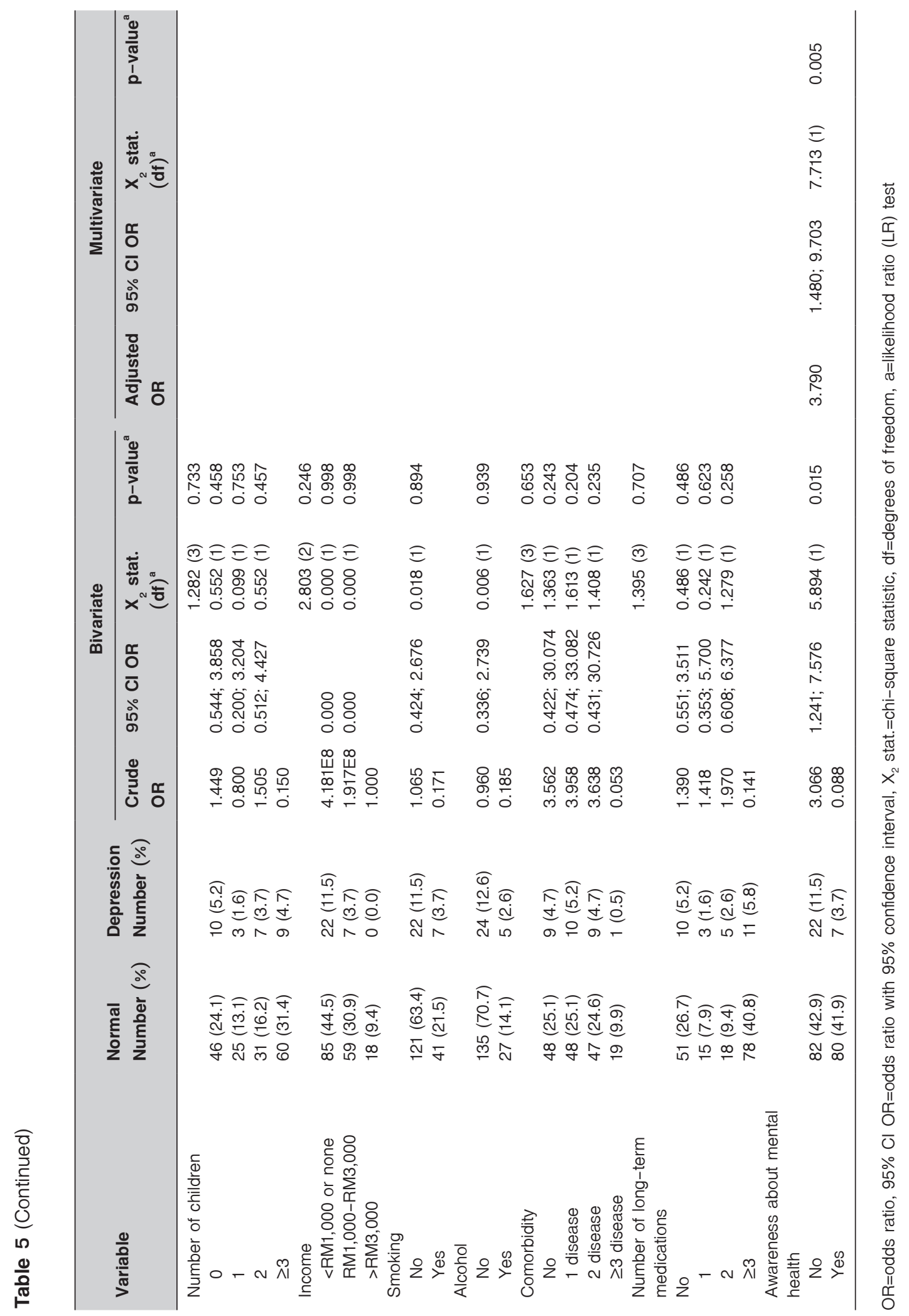




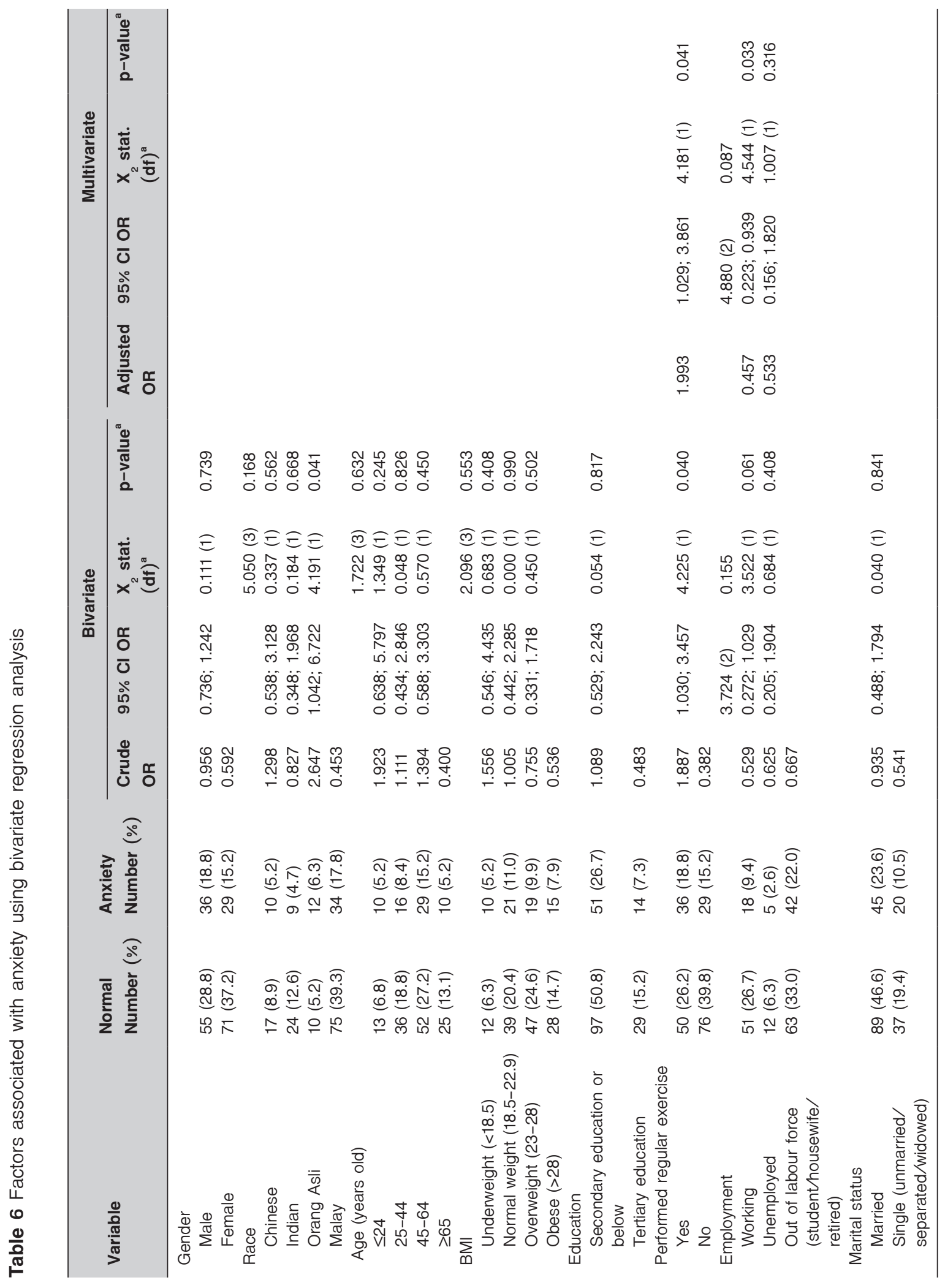




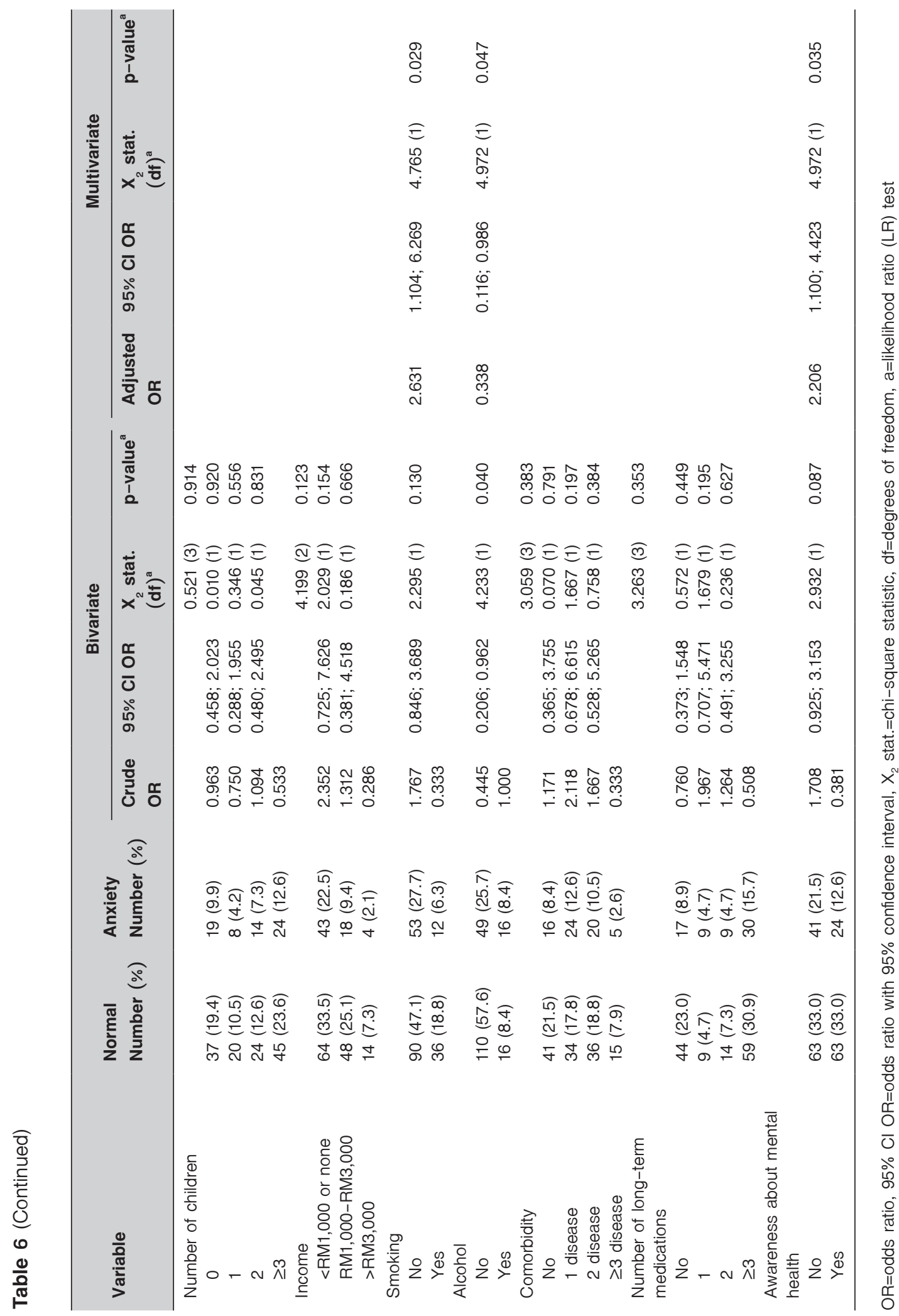




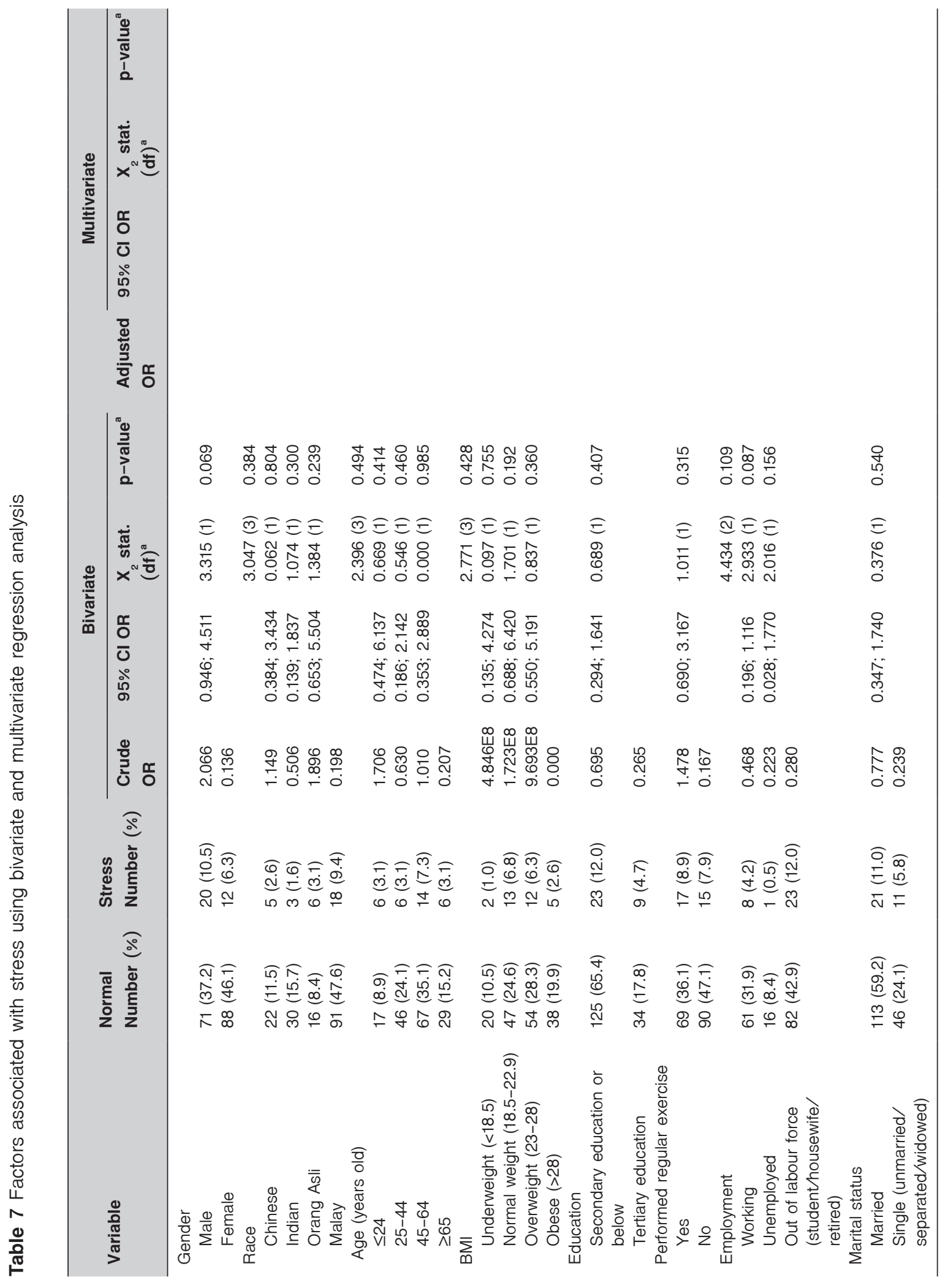




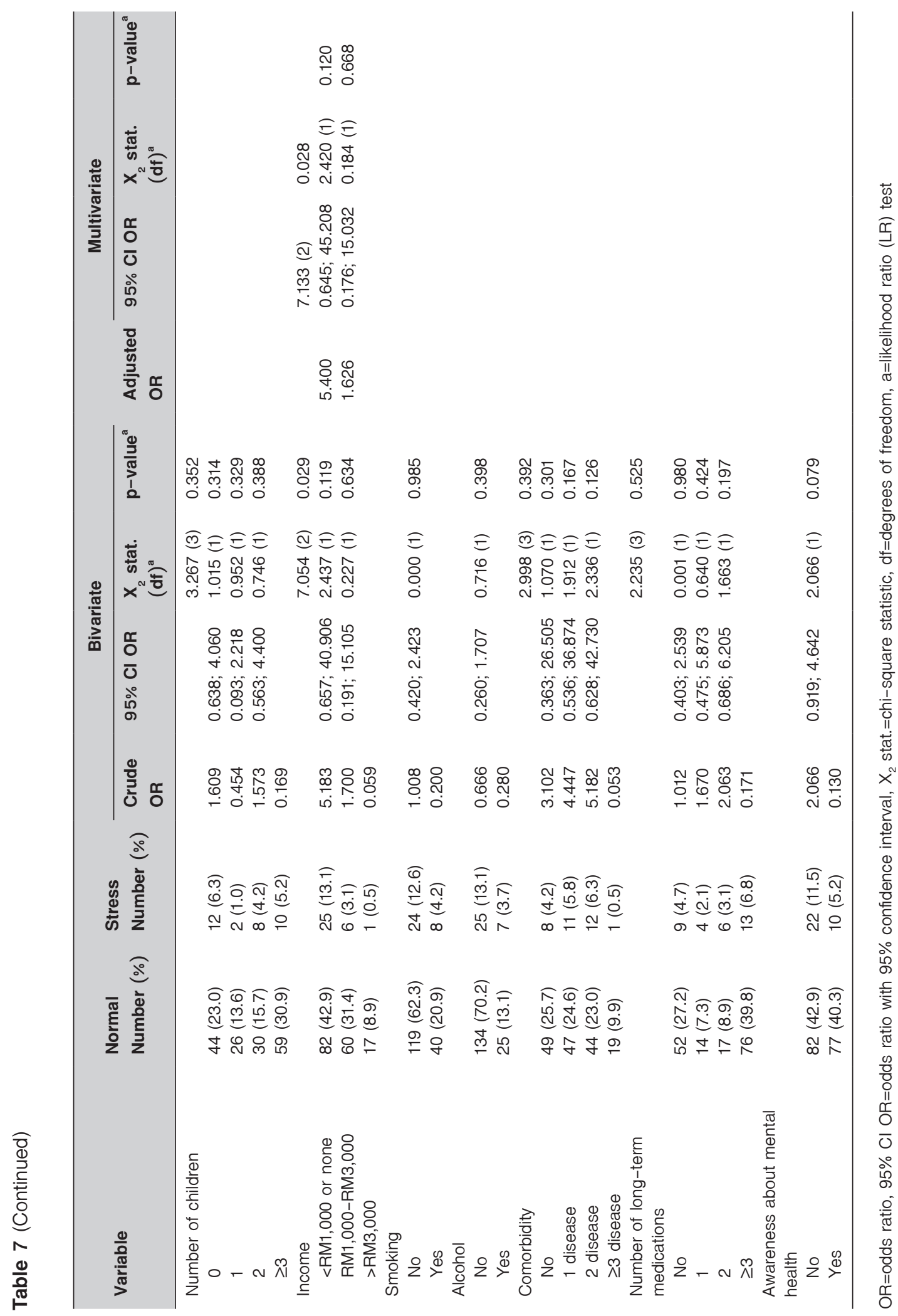


of 9.54, 8.83, and 7.81 in stress, depression, and anxiety, respectively. The pandemic was believed to have a negative effect on the mental health status of Malaysians as more people displayed moderate psychological symptoms during the COVID-19 era, corresponding to the DASS-21 scores of Table $1 .{ }^{12}$

Many studies have been conducted using DASS-21 targeting different populations globally. This study's findings were consistent with several studies which targeted chronic disease models where the prevalence of anxiety was highest. ${ }^{7,8}$ Conversely, it was observed that the participants from different countries had the highest scores in stress during the COVID-19 pandemic. ${ }^{13-15}$ The difference in outcomes could probably be due to attributes such as differences in culture, working environments, healthcare systems, and attitudes when facing uncertainty, especially during the pandemic.

This research was conducted using modifiable and non-modifiable risk factors. Race was found to be significant during the final model of multivariate analysis, and significantly higher odds of depression were shown among Orang Asli. The NHMS in 2015 reported that other Bumiputera had the highest rate of $\mathrm{MH}$ problems, although they are not the largest ethnic group in Malaysia. ${ }^{2}$ A study by Taylor et al. highlighted that psychological problems were increasingly highly detected in minor ethnic groups, for instance, African Americans. ${ }^{16}$ This could result from socioeconomic constraints, discrimination and poor education. ${ }^{17}$ Although there was no significant association between gender and PD in the current study, a metaanalysis found that more women than men had depressive symptoms. ${ }^{18}$ Lim et al. suggested that higher female proportion contributed to the heterogeneity in the aggregate prevalence of depression. ${ }^{18}$

$\mathrm{MH}$ awareness had a significant correlation with depression and anxiety in the current study. According to the $\mathrm{WHO}$, prevention programmes could improve public awareness and reduce depression rates drastically. ${ }^{1}$ According to Mental Atlas 2017, 123 countries had at least two functioning mental health promotion and prevention programmes. ${ }^{19}$ Livingston et al. found that young adults who were involved in anti-stigma media campaigns more likely to seek information regarding $\mathrm{MH}$ problems. ${ }^{20}$ A literature review was done by Dumesnil and Verger, which found that public awareness campaigns were able to improve public knowledge and attitudes about depression. ${ }^{21}$ It was found that 3 out of the 15 campaigns had reported a significant increase in the public intention for seeking professional care regarding depression. ${ }^{21}$

Surprisingly, the current study found a significant linkage between individuals who exercised regularly and more anxiety symptoms. Physical activity has usually been associated with positive health benefits, but conflicting results were observed in one study during research into the effect of exercise on $\mathrm{MH} .{ }^{22}$ Most studies have reported a reduction of anxiety symptoms in participants who engaged in physical activity, which was thought to likely involve biological and psychological factors. ${ }^{17,23}$ Another study found that the effect of exercise on $\mathrm{MH}$ could vary in different people, which could lead to these conflicting findings. ${ }^{24}$ Other studies have suggested that the most evidence-based treatment for PD is cognitive behaviour therapy (CBT), especially Internet CBT that can prevent the spread of infection during the pandemic. ${ }^{25,26}$

Anxiety symptoms were less likely to be reported in working adults. This finding was consistent with another study which reported that unemployed diabetics had higher odds of anxiety compared to those who were gainfully employed. ${ }^{17}$ Other studies have suggested that unemployed persons had feelings of instability and financial constraint, which could contribute to PD..$^{17,27}$

A significant association between smoking and anxiety was found in our study, as non-smokers had a higher risk of feeling anxiety. Morissette et al. reported a 
possible correlation between smoking and the expectation of reduction in anxiety symptoms. Another study supported the theory that nicotine may cause an anxiolytic effect depending on the timing, smoking context, and the administration route. ${ }^{28}$ However, this study's findings were inconsistent with other studies in which smokers had more anxiety symptoms. ${ }^{27,29}$ According to the Mental Health Foundation, nicotine brings an immediate relaxation and allows smokers to have a misconception about nicotine. However, this short-term feeling might lead the smokers to withdrawal symptoms and increased cravings. ${ }^{30}$

Pertaining to alcohol consumption, non-alcohol drinkers were less prone to anxiety. The findings of this study were similar to other studies showing an association between alcohol drinkers and anxiety symptoms. ${ }^{31,32}$ One study reported that alcohol was able to alter the levels of neurotransmitter. ${ }^{33}$ According to the Substance Abuse and Mental Health Services Administration, persistent and binge drinking leads to brain rewiring, and these individuals are more susceptible to anxiety. ${ }^{34}$ Individuals could return to their anxious state once the effects of the alcohol wear off. Kushner et al. proposed that short-term anxiety reductions from alcohol started a vicious feed-forward cycle of increasing the comorbidity of anxiety symptom and alcohol use. $^{33}$

Income was found to be significantly associated with stress, and patients with a monthly income of less than RM1000 had the highest odds of stress. Other studies have found financial constraint to be significantly correlates with PD. ${ }^{35,36}$ Sareen et al. found associations between low household income and lifetime mental disorders and suicidal attempts, and higher risk for incident mental disorders. ${ }^{37}$ Another study reported that cancer patients with low household income were at a higher risk of experiencing distress as they were unable to afford their medical bills. ${ }^{38}$ The mechanisms of development of $\mathrm{MH}$ disorders may include overcrowding, hunger, violence, social networks, and limited health-care access. ${ }^{37}$
While the study's findings furnish insight on the potential effects for mental health led by PD, it had several limitations. This study was conducted in a single facility and as such, the results could not be generalised to the prevalence of PD in the total population in Malaysia. Also, this was a cross-sectional study, and the causality of the results could not be explained, and other studies would be needed to examine this aspect of this problem. The size of the study sample is a crucial consideration for research. A decreasing number of patients during the data collection period caused by uncontrollable situations lowered the study's statistical power. The setback of considering a sample size of 191 instead of the required 304 in the study was compensated for by the post-hoc power analysis, which produced an excellent statistical power of over $80.0 \%$, fulfilling the standard threshold of $80.0 \%$. This study mainly used self-reported questionnaires to measure psychiatric symptoms and did not make a clinical diagnosis. The gold standard for establishing psychiatric diagnosis involves a structured clinical interview and functional neuroimaging. Future studies are required which correlate DASS-21 with neuroimaging results. ${ }^{39,40}$

\section{Conclusion}

PD has been increasing in recent years worldwide, and the problem has been exacerbated by the negative adverse impacts caused by the COVID-19 pandemic. Untreated psychological disorders lead to severe health problems. Thus, having a good grasp of the key determinants of the probable development of PD in patients is essential. The results of this study revealed that anxiety had the highest prevalence among warded adult patients in Hospital Tapah. Race and $\mathrm{MH}$ awareness were the significant risk factors for depression. Factors associated with anxiety included regular exercise, employment, smoking, alcohol consumption, and $\mathrm{MH}$ awareness. Income was found to be significantly associated with stress. Despite a sample size constraint, the study's findings were confirmed following 
post-hoc analysis. Further studies should be conducted for better understanding to help propose intervention measures to help remedy this condition. Future research should consider to correlate DASS-21 with neuroimaging results since the criteria for making a psychiatric diagnosis involve a structured clinical interview and functional neuroimaging.

\section{Acknowledgement}

We express our deepest gratitude to the DirectorGeneral of Health, Malaysia, for his permission for publication and the Director of Hospital Tapah for his approval in conducting this research. Thanks are also due to our colleagues for their kind assistance, especially Ms. Ang Ju Ying from the Clinical Research Centre Perak.

\section{Conflict of interest}

All authors have declared no conflicts of interest.

\section{References}

1. World Health Organization. Investing in mental health. Geneva: WHO; 2003.

2. Ministry of Health Malaysia. National health \& morbidity survey 2015. Malaysia: Institute for Public Health; 2015.

3. World Health Organization. Mental health atlas 2011. Geneva: WHO; 2011.

4. Tsuey Chong S, Mohamad MS, Er AC. The mental health development in Malaysia: History, current issue and future development. Asian Social Science 2013;9:1-8.

5. Biologically-inspired biomarkers for mental disorders. EBioMedicine 2017;17:1-2.

6. Guan NC. A review of depression research in Malaysia. Medical Journal of Malaysia 2014;69(Suppl A):42-5.

7. Tee CA, Salido EO, Reyes PWC, Ho RC, Tee ML. Psychological State and Associated Factors During the 2019 Coronavirus Disease (COVID-19) Pandemic Among Filipinos with Rheumatoid Arthritis or Systemic Lupus Erythematosus. Open Access Rheumatol Res Rev 2020;12:215.

8. Le TA, Le MQT, Dang AD, Dang AK, Nguyen CT, Pham HQ, et al. Multi-level predictors of psychological problems among methadone maintenance treatment patients in different types of settings in Vietnam. Subst Abus Treat Prev Policy 2019;14:1-10.

9. Rehman A Ur, Kazmi SF. Prevalence and level of depression, anxiety and stress among patients with type-2 diabetes. Annals of PIMS-Pakistan Institute Med Sci 2015;11:81-6.

10. Hosmer DW, Lemeshow S, Sturdivant RX. Applied logistic regression. $3^{\text {rd }}$ ed. Hoboken: John Wiley \& Sons; 2013.

11. World Health Organization. Depression and other common mental disorders: global health estimates. Geneva: WHO; 2017.

12. Wang $C$, Tee M, Roy AE, Fardin MA, Srichokchatchawan W, Habib HA, et al. The impact of COVID-19 pandemic on physical and mental health of Asians: a study of seven middleincome countries in Asia. PLoS One 2021;16:e0246824.

13. Wang C, Tripp C, Sears SF, Xu L, Tan Y, Zhou D, et al. The impact of the COVID-19 pandemic on physical and mental health in the two largest economies in the world: a comparison between the United States and China. J Behav Med 2021;1:1.

14. Wang C, López-Núñez MI, Pan R, Wan X, Tan Y, Xu L, et al. The impact of the COVID-19 pandemic on physical and mental health in China and Spain: cross-sectional study. JMIR Form Res 2021;5:e27818.

15. Wang C, Fardin MA, Shirazi M, Pan R, Wan X, Tan Y, et al. Mental health of the general population during the 2019 coronavirus disease (COVID-19) pandemic: a tale of two developing countries. Psychiatry Int 2021;2:71-84.

16. Taylor DJ, Lichstein KL, Durrence HH, Reidel BW, Bush AJ. Epidemiology of insomnia, depression, and anxiety. Sleep 2005;28:1457-64.

17. Kaur G, Tee GH, Ariaratnam S, Krishnapillai AS, China K. Depression, anxiety and stress symptoms among diabetics in Malaysia: a cross sectional study in an urban primary care setting. BMC Fam Pract 2013;14:69.

18. Lim GY, Tam WW, Lu Y, Ho CS, Zhang MW, Ho RC. Prevalence of depression in the community from 30 countries between 1994 and 2014. Sci Reports 2018;8:1-10.

19. World Health Organization. Mental health atlas 2017. Geneva: WHO; 2017.

20. Livingston JD, Tugwell A, Korf-Uzan K, Cianfrone M, Coniglio C. Evaluation of a campaign to improve awareness and attitudes of young people towards mental health issues. Soc Psychiatry Psychiatr Epidemiol 2013;48:965-73. 
21. Dumesnil $H$, Verger $P$. Public awareness campaigns about depression and suicide: a review. Psychiatric Services 2009; $60: 1203-13$

22. Chekroud SR, Gueorguieva R, Zheutlin AB, Paulus M, Krumholz HM, Krystal JH, et al. Association between physical exercise and mental health in 1.2 million individuals in the USA between 2011 and 2015: a cross-sectional study. Lancet Psychiatry 2018;5:739-46.

23. Khuwaja AK, Lalani S, Dhanani R, Azam IS, Rafique G, White F. Anxiety and depression among outpatients with type 2 diabetes: A multi-centre study of prevalence and associated factors. Diabetol Metab Syndr 2010;2:72

24. Anxiety and Depression Association of America. Exercise for stress and anxiety [monograph on the Internet]. United States: Anxiety and Depression Association of America; 2021 [cited 2021 May 10]. Available from: https://adaa.org/iving-withanxiety/managing-anxiety/exercise-stress-and-anxiety

25. Ho Su Hui C, Ho CS, Chee CY. Mental health strategies to combat the psychological impact of coronavirus disease 2019 (COVID-19) beyond paranoia and panic. Ann Acad Med Singap 2020;49:155-60.

26. Zhang MWB, Ho RCM. Moodle: The cost effective solution for internet cognitive behavioral therapy (I-CBT) interventions. Technol Heal Care 2017;25:163-5.

27. Hassan R, Zulkifli MM, Ahmad I, Yusoff SSM. Depression, anxiety and stress among obese patients with chronic illnesses: Prevalence and associated factors in North East Malaysia. Bangladesh J Med Sci 2019;18:252-9.

28. Morissette SB, Tull MT, Gulliver SB, Kamholz BW, Zimering RT. Anxiety, anxiety disorders, tobacco use, and nicotine: a critical review of interrelationships. Psychological Bulletin 2007;133: 245-72.

29. Rashid RA, Kanagasundram S, Danaee M, Majid HA, Sulaiman $\mathrm{AH}$, Zahari MMA, et al. The prevalence of smoking, determinants and chance of psychological problems among smokers in an urban community housing project in Malaysia. Int $\mathrm{J}$ Environ Res Public Health 2019;16:1762.

30. Mental Health Foundation. Smoking and mental health [monograph on the Internet]. United Kingdom: Mental Health Foundation; 2016 [cited 2020 Dec 6]. Available from: https://www. mentalhealth.org.uk/a-to-z/s/smoking-and-mental-health
31. Tembo C, Burns S, Kalembo F. The association between levels of alcohol consumption and mental health problems and academic performance among young university students. PLoS One 2017. doi.org/10.1371/journal.pone.0178142.

32. Villarosa MC, Moorer KD, Madson MB, Zeigler-Hill V, Noble JJ. Social anxiety and alcohol-related negative consequences among college drinkers: do protective behavioral strategies mediate the association? Psychol Addict Behav 2014;28: 887-92.

33. Kushner MG, Abrams K, Borchardt C. The relationship between anxiety disorders and alcohol use disorders: a review of major perspectives and findings. Clin Psychol Rev 2000;20: 149-71.

34. Watkins M. The Connection between Anxiety and Alcohol [monograph on the Internet]. United States: American Addiction Centers; 2021 [cited 2021 May 10]. Available from: https:// americanaddictioncenters.org/alcoholism-treatment/anxiety

35. Yeshaw Y, Mossie A. Depression, anxiety, stress, and their associated factors among Jimma University staff, Jimma, Southwest Ethiopia, 2016: a cross-sectional study. Neuropsychiatr Dis Treat 2017;13:2803-12.

36. Abdel Wahed WY, Hassan SK. Prevalence and associated factors of stress, anxiety and depression among medical Fayoum University students. Alexandria J Med 2017;53:77-84.

37. Sareen J, Afifi TO, McMillan KA, Asmundson GJG. Relationship between household income and mental disorders: findings from a population-based longitudinal study. Arch Gen Psychiatry 2011;68:419-27.

38. McMullen M, Lau PKH, Taylor S, McTigue J, Cook A, Bamblett $M$, et al. Factors associated with psychological distress amongst outpatient chemotherapy patients: an analysis of depression, anxiety and stress using the DASS-21. Appl Nurs Res 2018;40: 45-50.

39. Husain SF, Yu R, Tang TB, Tam WW, Tran B, Quek TT, et al. Validating a functional near-infrared spectroscopy diagnostic paradigm for Major Depressive Disorder. Sci Reports 2020;10:1-9.

40. Ho CSH, Lim LJH, Lim AQ, Chan NHC, Tan RS, Lee SH, et al. Diagnostic and predictive applications of functional near-infrared spectroscopy for major depressive disorder: a systematic review. Front Psychiatry 2020;11:378. 